\title{
Biodegradable films and spray coatings as eco-friendly alternative to petro-chemical derived mulching films
}

\author{
G. Vox, ${ }^{1}$ G. Santagata, ${ }^{2}$ M. Malinconico, ${ }^{2}$ B. Immirzi, ${ }^{2}$ G. Scarascia Mugnozza, ${ }^{1}$ \\ E. Schettini ${ }^{1}$ \\ ${ }^{1}$ Department of Agricultural and Environmental Science (DISAAT), University of Bari, Bari, Italy; \\ ${ }^{2}$ Institute of Chemistry and Technology of Polymers, CNR, Pozzuoli, Naples, Italy
}

\begin{abstract}
The use of plastic mulching films in horticulture causes the serious drawback of huge amount of wastes to be disposed of at the end of their lifetime. Several pre-competitive research products based on raw materials coming from renewable sources were recently developed to be used as biodegradable materials for soil mulching. Biodegradable materials are designed in order both to retain their mechanical and physical properties during their using time and to degrade at the end of their lifetime. These materials can be integrated directly in the soil in order to biodegrade because the bacterial flora transforms them in carbon dioxide or methane, water and biomass. The innovative materials can be obtained using natural polymers, such as starch, cellulose, chitosan, alginate and glucomannan. Biodegradable extruded mulching films were performed by means of thermo-plasticizing process. Spray mulch coatings were realized directly in field, by spraying water solutions based on natural polysaccharides, thus covering the cultivated soil with a protective thin geo-membrane. In this paper an overview on the formulation development, processing understanding, field performance, mechanical and radiometric properties of these innovative materials for soil mulching is presented. In field the
\end{abstract}

Correspondence: Evelia Schettini, Department of Agricultural and Environmental Science (DISAAT) - University of Bari, via Amendola 165/A 70126 Bari, Italy, giuliano.vox@uniba.it

E-mail: evelia.schettini@uniba.it

Key words: spray technique, polysaccharides, eco-sustainability, mechanical properties.

Acknowledgements: the research described has been carried out under the project EC RTD QLRT 'Environmentally friendly mulching and low tunnel cultivation - Bioplastics' (Contract $n^{\circ}$ QLK5-CT-2000-00044) and under the project LIFE Environment "Biodegradable coverages for sustainable agriculture - BIO.C0.AGRI" (LIFE03 ENV/IT/000377), both funded by the European Commission.

The experimental tests, the data processing and the editorial work must be shared, within the competencies of the research groups, equivalently among the Authors.

(C) Copyright G. Vox et al., 2013

Licensee PAGEPress, Italy

Journal of Agricultural Engineering 2013; XLIV(s2):e44

doi:10.4081/jae.2013.s2.e44

This article is distributed under the terms of the Creative Commons Attribution Noncommercial License (by-nc 3.0) which permits any noncommercial use, distribution, and reproduction in any medium, provided the original author(s) and source are credited. biodegradable mulching films showed suitable mechanical properties if compared to the low density polyethylene films. The radiometric properties and their effect on the temperature condition and on weed control in the mulched soil were evaluated too. At the end of their lifetime the biodegradable materials were shattered and buried into the soil together with plants.

\section{Introduction}

Synthetic petro-chemical based mulching films are worldwide used in agriculture to suppress weed, to reduce the loss of moisture from the soil, to preserve the plants and the edible products from the soil diseases and from the dirt. The main advantages of the plastic mulches are the decrease of the use of chemicals in weed control, the reduction of water consumption, the faster crop development, the improvement of the plants health and of the yield quality. In intensive cultivation low density polyethylene (LDPE) mulching films are commonly used for their mechanical and thermo-optical properties, chemical and microbial degradation resistance, easy processability and low cost. Opaque mulching films do not allow photosynthetically active radiation (PAR) passing through thus preventing weed growth, while transparent mulches warm the substrate hastening early growth and blooming. At the end of their lifetime the plastic films must be removed with high cost for the growers and with environmental negative consequences connected to their collection, disposal of and recycling process.

In order to develop eco-friendly alternatives to synthetic petro-chemical polymers, novel biodegradable materials have been developed using raw materials from renewable origin. The biodegradable materials have to retain their mechanical and physical properties while in use and must be biodegradable or compostable at the end of their life, degrading via micro-organisms into carbon dioxide or methane, water and biomass. These materials can be obtained by means of thermal film forming processes, casting and spraying techniques.

Biodegradable mulching films can be made by thermo-plasticizing film forming process, using natural or synthetic biodegradable polymers such as starch, poly(lactic acid) (PLA) or polyvinyl alcohol (PVOH) as raw material. Starch based films (Mater-Bi, Novamont Co., Novara, Italy) have been successfully tested (Bastioli, 1998; Briassoulis, 2006a, 2006b, 2007; Martin-Closas et al., 2008; Scarascia et al., 2004; Scarascia et al., 2006; Vox and Schettini, 2007; Malinconico et al., 2008), but their cost was higher than the cost of LDPE films.

Biodegradable mulching coatings can be made by spraying water solutions directly in field thus covering the soil with a protective thin geo-membrane. The water solutions are based on natural polysaccharides, such as sodium alginate, galactomannan, chitosan and cellulose (Schettini et al., 2007; Schettini et al., 2013; Immirzi et al., 2009), and on hydrolyzed proteins (Sartore et al., 2013).

This paper investigates the formulation development, processing 
understanding, field performance and the mechanical properties of starch-based extruded films and spray mulching coatings. These biodegradable mulches, prepared using natural polymers, were tested in field also in order to verify if they accomplish the mulching task of weed control and if they have the required lifetime.

\section{Materials and methods}

Biodegradable mulching films and water-born spray coatings were tested at the experimental farm of the University of Bari from 2001 to 2005 (Scarascia et al., 2004; Schettini et al., 2007; Vox and Schettini, 2007). The biodegradable mulches and commercial LDPE films, used as control, were applied inside greenhouses, under low tunnels and in open-air; they varied in thickness and colour, as shown in Table 1.

The use of biodegradable films and spray coatings did not require any particular change in agronomical practices. The soil preparation, such as ploughing and tilling, do not differ for the application of an extruded film or a spray coating (Malinconico et al., 2008). The soil and the growing media should be without residues of previous cultivations and large size stones; the surface should be flat to prevent holes and cracks of the film or coating, which can facilitate weed growth. Drip irrigation, irrigation by hose and by porous tube, which are the irrigation methods used in presence of plastic mulching films, were also suitable for the biodegradable mulches. The agrochemical products, such as fertilizers, insecticides, fungicides, herbicides and so on, were employed both for biodegradable mulches and for LDPE films in the same period and at the same doses.

The starch-based raw material (Mater-Bi, Novamont Co., Novara, Italy) was extruded using the LDPE film extrusion line with minor modifications (Briassoulis, 2006b, 2007). The films tested varied in different kind and quantity of biodegradable master batches and of stabilizers used, with a percentage not revealed since these formulations are proprietary. As done for LDPE films, the installation of biodegradable mulching films in field was performed by machine (Figure 1) or manually.

An innovative approach of mulch forming is the use of the spray methodology (Figure 2; Malinconico et al., 2008). Polysaccharides, as agarose, galactomannans (guar gum, locust bean gum) and sodium alginate, are chosen as basic ingredients of the water-born solutions for their biodegradability, biocompatibility and non-toxicity and for their intrinsic properties to form water resistant coatings (Avella et al., 2007; Mormile et al., 2007). In order to improve the mulching function and the tensile strength of the spray coating, fillers (cellulose fibres, carbon black, fine bran of wheat and powdered seaweeds), plasticizing polymers (hydroxyethylcellulose), and natural plasticizers (glycerol and polyglycerol) were mixed to the polymeric matrices. Three different spray mulching coatings were developed (Malinconico et al., 2008) and the polysaccharides concentration used determined coating's thickness and lifespan. The coating coded MY consisted of a water mixture of locust bean gum and guar gum (PSS20 Protective Surface System, PSI Polysaccharide Industries AB, Stockholm, Sweden), with a concentration of about 1.5\% of each component with the addition of a non-gelling concentration of agarose. To this blend $1.5 \%$ of glycerol and $2 \%$ of carbon black were added; the latter was added to the water solution to make the coating opaque to the PAR radiation in order to control the weed growth (Figure 2(a)). The coating coded MC was based on PSS20

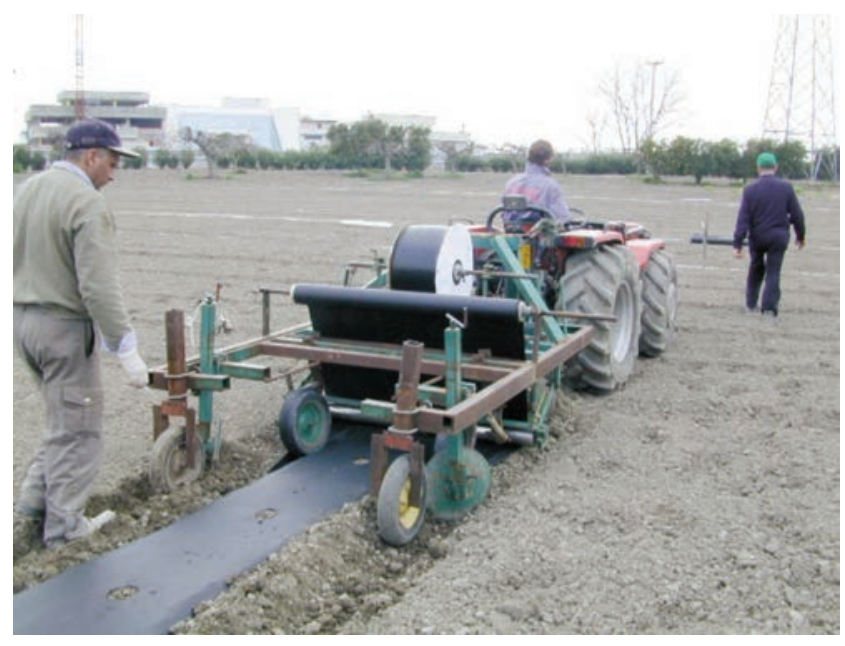

Figure 1. Mechanical installation for soil mulching of the biodegradable melt-extruded film for a low-tunnel cultivation at the experimental farm of the University of Bari (Italy).

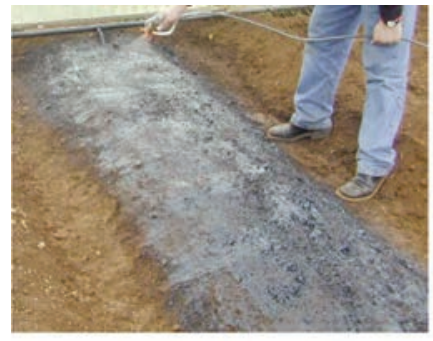

(a)

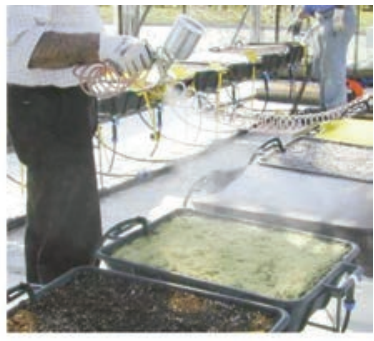

(b)
Figure 2. Soil mulching made by means of spraying techniques applying biodegradable water-born solutions: MY on soil raised beds inside a greenhouse (a) and MA on the growing media in a cultivation carried out in pots $(\mathbf{b})$.

Table 1. Biodegradable and LDPE extruded mulching films and biodegradable water-born spray coating tested at the University of Bari.

\begin{tabular}{lllll} 
Code & Technique & Raw material & Colour & Thickness $(\mu \mathrm{m})$ \\
MB1 & Extrusion & Mater-Bi & Black & 50 \\
MB2 & Extrusion & Mater-Bi & Black & 25 \\
\hline MB3 & Extrusion & Mater-Bi & Black & 15 \\
MP1 & Extrusion & LDPE & Black & 40 \\
\hline MY & Spray & PSS20, carbon black & Black & $18-35$ \\
MC & Spray & PSS20, cellulose paper & White & $1500-2500$ \\
\hline MA & Spray & Sodium Alginate, seaweeds, bran of wheat & Brown & $3000-5000$ \\
\hline
\end{tabular}


formulation added with cellulose fibres, able to improve the mechanical resistance of the coating in wet environment, by forming a polymeric texture. Under wetting conditions the MC coating could follow the ground shape withstanding the forces of cracking soil due to the plasticizing action of water. The coating coded MA was developed by using sodium alginate for $33 \%$, hydroxyethylcellulose for $17 \%$ and polyglycerol for $50 \%$. This blend was sprayed on the soil, which was previously covered with a pulverized mixture of seaweeds flour and fine bran of wheat in order to improve the mechanical response of the coating.

The three water-born solutions were applied by means of an airbrush, using a high pressure spray machine, commonly employed in agriculture. The side slope of raised beds should be limited in order to avoid a possible sliding of the water-born coating at the liquid state during the spraying before the dry process (Figure 2 (a)). In pot cultivation the level of the growing media must be lower than the edge of the pot in order to contain the spray coatings (Figure 2(b)). In presence of plants a protection must be used to maintain plants clean during the spraying (Figure 3). In case of seeds or bulbs sowed before the spraying, buds hole the coatings without any problem (Figure 4) while seedlings transplanting can be performed holing the coating when the drying process of the coating is completed.

After the harvests, the biodegradable films and water-born coatings were shattered together with the plants, by means of tilling machine, in order to accelerate the degradation process by the action of the microorganisms (Figure 5).

Mechanical laboratory tests were carried out at ICTP on samples of the biodegradable and LDPE mulching films taken before their installation, and on laboratory samples of the water-born biodegradable coatings, obtained spraying the water-born solutions on glasses and peeling them once dried. Mechanical properties play a fundamental role for mulches, influencing their durability and functionality. The tensile stress and strain at break for the LDPE, the biodegradable films and the MY water-born coating were measured by a dynamometer (Instron Mod. 4301), in accordance with the ISO 5893 standard (ISO 5893, 2002). For each sampling five specimens, obtained with a regular punch cutter and with the dimension of $0.5 \mathrm{~cm} \times 2.5 \mathrm{~cm}$, were tested at room temperature, at crosshead rate of $10 \mathrm{~mm}$ min-1 and at relative humidity equal to $35 \%$.

The MA and MC water-born coatings were not self-standing materials but they took their support from the soil beneath, thus the mechanical characterization of the MA and MC coating samples was not feasible with the dynamometer and it was carried out by the "puncture test", an empiric test described by Malinconico et al (2008). The puncture test consists in penetrating the specimens with a spherical dart that, moving at constant rate, pierces the samples until the laceration of the same; for this kind of empirical test, the maximum load (N) as a func-

Table 2. Mechanical properties of the biodegradable and LDPE extruded mulching films and of the MY biodegradable water-born coating.

\begin{tabular}{lccc} 
& Young Modulus (MPa) & Tensile stress at break (MPa) & Tensile strain at break (\%) \\
MB1 & $246( \pm 20 \%)$ & $11( \pm 20 \%)$ & $380( \pm 30 \%)$ \\
MB2 & $456( \pm 20 \%)$ & $11( \pm 20 \%)$ & $262( \pm 30 \%)$ \\
\hline MB3 & $265( \pm 20 \%)$ & $18( \pm 20 \%)$ & $255( \pm 30 \%)$ \\
MP1 & $270( \pm 13 \%)$ & $20( \pm 20 \%)$ & $578( \pm 30 \%)$ \\
\hline MY & $48.8 \pm 6.4$ & $2.45 \pm 0.21$ & $4.10 \pm 1.2$ \\
\hline
\end{tabular}

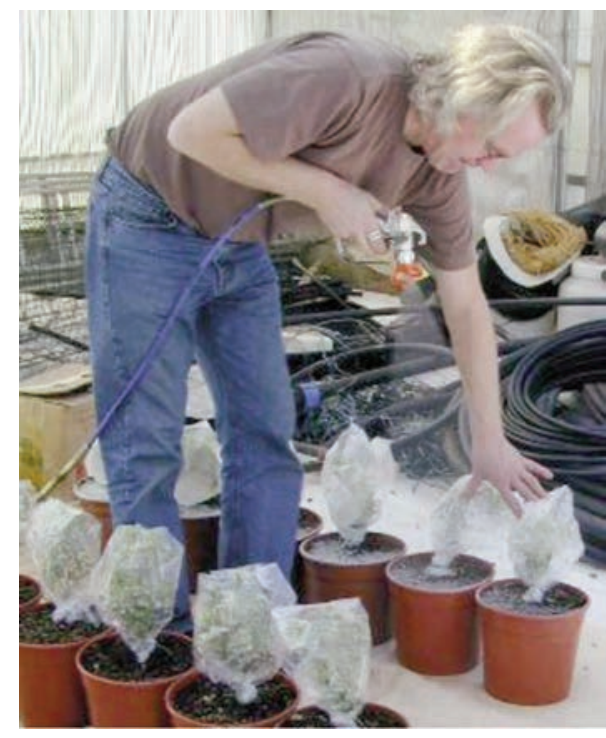

Figure 3. Soil mulching with the MA biodegradable water-born coating realised by means of spraying techniques in a cultivation carried out in pots at the experimental farm of the University of Bari (Italy).

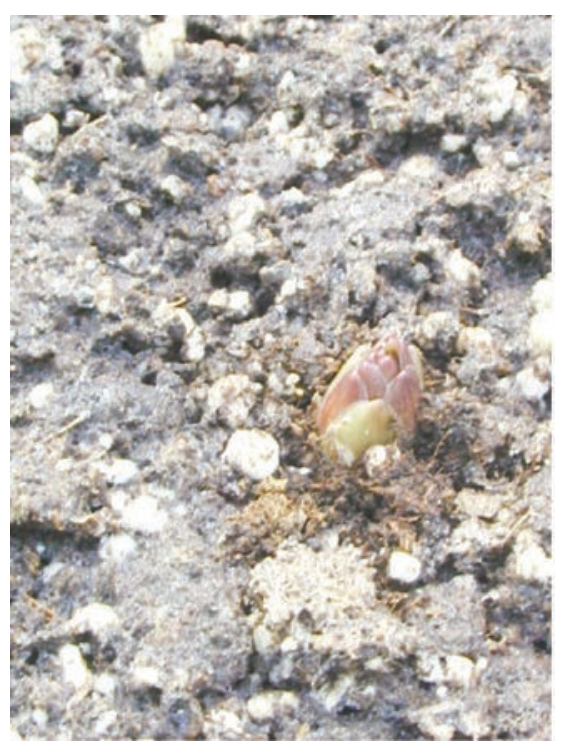

Figure 4. Emergence of bulbs sowed before the spraying, in a cultivation carried out in pots at the experimental farm of the University of Bari (Italy). 
tion of the displacement (mm) was recorded. For each time of samples drawing out, seven specimens were tested.

\section{Results and discussion}

The average values of the tensile stress and strain at break, and of the Young Modulus relative to the biodegradable and LDPE mulching films and to the MY water-born coating are reported in Table 2. The mechanical tests were carried out in the longitudinal direction (extrusion direction) because in this direction the tensile properties of the biodegradable films vary more regularly than in transversal direction. This was probably due to the anisotropy of biodegradable material respect to the enhanced regular macromolecular organization of LDPE film.

The thickness of the MY water-born coating varied from 18 to $35 \mu \mathrm{m}$, due to the presence of carbon black whose distribution was not homogeneous. The biodegradable films and the MY coating showed lower values of tensile stress and strain at break than the value obtained for the MP1 LDPE film (Table 2). The MB2 biodegradable mulching film was characterised by the highest value of the Young Modulus, equal to $456 \mathrm{MPa}$, while the MY coating by the lowest value of tensile stress at break (2.45 MPa), of tensile strain at break (4.10\%) and of the Young Modulus (48.8 MPa). According to the EN 13655 (EN 13655, 2003), black LDPE mulching films must have a tensile stress at break higher than $16 \mathrm{MPa}$ and a tensile strain at break higher than $180-250 \%$, being the above range a function of the thickness. Even though the values of the tensile stress at break evaluated for the MB1 and MB2 black biodegradable films were lower (Table 2), their mechanical properties

Table 3. Mechanical properties of the MA and MC water-born coatings.

\begin{tabular}{llc} 
& Maximum load $(\mathrm{N})$ & Displacement $(\mathrm{mm})$ \\
MA & $3.4 \pm 1.6$ & $1.058 \pm 0.015$ \\
MC & $122.5 \pm 2.3$ & $0.408 \pm 0.030$ \\
\hline
\end{tabular}

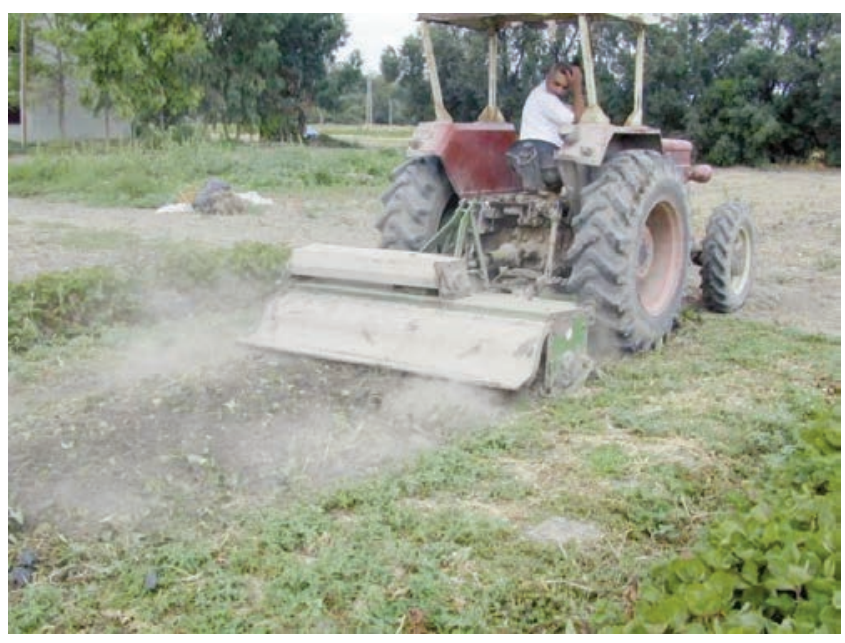

Figure 5. Shattering by a milling machine of biodegradable mulching films at the end of the cultivation at the experimental farm of the University of Bari (Italy). were sufficiently in the range necessary to be installed and to be used from planting to harvesting applying the same cultivation techniques currently used for LDPE mulching films (Vox et al., 2005; Briassoulis, 2006a; Scarascia Mugnozza et al., 2006; Malinconico et al, 2008).

The mechanical properties of the MC and MA water-born coatings, i.e. the maximum load and the displacement evaluated by means of the "puncture test", are reported in Table 3. The MC and MA coatings were characterised by inhomogeneous surfaces and irregular thickness: the MA coating had a thickness from 3000 to $5000 \mu \mathrm{m}$ while the MC coating from 1500 to $2500 \mu \mathrm{m}$. The mechanical performance was adequate for their durability and functionality from planting to harvesting.

The biodegradable mulching films and the water-born coatings created a physical barrier to prevent airborne weed seeds.

The MB1 and MB2 films lasted 9 months during a strawberry cultivation (Scarascia Mugnozza et al., 2006) and MB3 was used for 5 months during a melon cultivation (Vox et al., 2005). The Mater-Bi mulching films recorded a lifetime longer than the one of other biodegradable films reported in literature: from 2 to 5 months when Mater-Bi mulching films are used in an open-air cultivation (Novamont, 2007); 1.5 months for a Mater-Bi mulching film of $18 \mathrm{~m}$ (Martin-Closas et al., 2002); 3 months for a copolyester biodegradable mulching film (Tocchetto et al., 2002), and 3.5 months for a modified starch polymer blended with aliphatic polyesters (Halley et al., 2001).

The MA and MC coatings lasted for 6 months and the MY coating for almost 5 months. These water-born coatings can be compared in literature to a sprayable mulch colour synthetic latex film (Mahmoudpour and Stepleton; 1997) and to a biodegradable polymeric mulching spray coatings based on hydrolyzed proteins (Sartore et al., 2013). The sprayed mulch described by Mahmoudpour and Stepleton (1997) was used in open air and it was damaged after two weeks after their application due to a hail storm. The mulching coating based on hydrolyzed proteins remained continuous and regular for 9 months keeping its mulching effect with few irregularities on the surface around the plants, where water was delivered by the drip irrigation system (Sartore et al., 2013).

\section{Conclusions}

The employment of biodegradable materials based on renewable raw sources represent a valid challenge for the development of eco-friendly materials able to compete with petro-chemical polymers due to their sustainability and inexhaustibility. The biodegradable starch-based extruded films and the biodegradable sprayable water-born polysaccharides based coatings had mechanical properties and field performance comparable to low density polyethylene mulching films. Future research will be particularly addressed at improving the mechanical properties, in order to lengthen their lifetime and also to produce films having a higher roll width.

\section{References}

Avella M., Di Pace E., Immirzi B., Impallomeni G., Malinconico M., Santagata G. 2007. Addition of glycerol plasticizer to seaweeds derived alginates: Influence of microstructure on chemical-physical properties. Carbohyd Polym 69 (3): 503-511.

Bastioli C. 1998. Properties and applications of Mater-Bi starch-based materials. Polym Degrad Stabil 59: 263-272.

Briassoulis D. 2006a. Mechanical behaviour of biodegradable agricultural films under real field conditions. Polym Degrad Stabil 91 (6): 


\section{6-1272.}

Briassoulis D. 2006b. Mechanical performance and design criteria of biodegradable low-tunnel films. J Polym Environ 14 (3): 289 - 307.

Briassoulis D. 2007. Analysis of the mechanical and degradation performances of optimised agricultural biodegradable films. Polym Degrad Stabil 92 (6): 1115-1132.

EN 13655 2003. Mulching thermoplastic films for use in agriculture and horticulture. CEN - European Committee for Standardization, Bruxelles.

Halley P., Rutgers R., Coombs S., Kettels J., Gralton J., Christie G., Jenkins M., Beh H., Griffin K., Jayasekara R., Lonergan G. 2001. Developing biodegradable mulch films form starch-based polymers. Starch 53: 362-367.

Immirzi B., Santagata G., Vox G., Schettini E. 2009. Preparation, characterisation and field testing of a biodegradable sodium alginatebased spray mulch. Biosyst Eng 102: $461-472$.

ISO 58932002 . Rubber and plastics test equipment - Tensile, flexural and compression types (constant rate of traverse) - Specification. International Organization for Standardization.

Mahmoudpour M. A., Stepleton J. J. 1997. Influence of sprayable mulch colour on yield of eggplant (Solanum melongena L. cv. Millionaire) Sci Hortic 70 (4): 331-338.

Malinconico M., Immirzi B., Santagata G., Schettini E., Vox G., Scarascia Mugnozza G. 2008. Chapter 3: An overview on innovative biodegradable materials for agricultural applications in "Progress in Polymer Degradation and Stability Research", H. W. Moeller Editor, Nova Science Publishers, Inc. NY USA, ISBN: 978-1-60021828-6: 69-114.

Martin-Closas L., Soler J., Pelacho A. M. 2002. Effect of different biodegradable mulch materials in an organic tomato production system. Proc. "Biodegradable materials and natural fibre composite in agriculture and horticulture". Hannover, Germany, 2-4/06/2002. p. 7885.

Martin-Closas L., Pelacho A.M., Picuno P., Rodríguez D. 2008. Properties of new biodegradable plastics for mulching, and characterization of their degradation in the laboratory and in the field.
Acta Horticulturae 801(1): 275-282

Mormile P., Petti L., Rippa M., Immirzi B., Malinconico M., Santagata G. 2007. Monitoring of the degradation dynamics of agricultural films by IR thermography. Polym Degrad Stabil 92: 777-784.

Novamont. 2007. Mater Bi. http://www.materbiagro.com/ing/caratteristiche.html

Scarascia-Mugnozza G., Schettini E., Vox, G. 2004. Effects of the Solar Radiation on the Radiometric Properties of Biodegradable Films for Agricultural Applications. Biosyst Eng 87 (4): 479-487.

Scarascia-Mugnozza G., Schettini E., Vox G., Malinconico M., Immirzi B., Pagliara S. 2006. Mechanical properties decay and morphological behaviour of biodegradable films for agricultural mulching in real scale experiment. Polym Degrad Stabil 91 (11): 2801-2808.

Schettini E., Vox G., De Lucia B. 2007. Effects of the radiometric properties of innovative biodegradable mulching materials on snapdragon cultivation. Sci Hortic. 112 (4): 456-461.

Schettini E., Santagata G., Malinconico M., Immirzi B., Scarascia Mugnozza G., Vox G. 2013. Recycled wastes of tomato and hemp fibres for biodegradable pots: Physico-chemical characterization and field performance. Resour Conserv Recy 70: 9- 19.

Sartore L., Vox G., Schettini E. 2013. Preparation and Performance of Novel Biodegradable Polymeric Materials Based on Hydrolyzed Proteins for Agricultural Application. J. Polym. Environ. doi: 10.1007/s10924-013-0574-2

Tocchetto R. S., Benson R. S., Dever M. 2002. Outdoor weathering evaluation of carbon-black-filled, biodegradable copolyester as substitute for traditionally used, carbon-black-filled, nonbiodegradable, high-density polyethylene mulch films. J Polym Environ 9 (2): 57 62.

Vox G., Schettini E., Scarascia-Mugnozza, G. 2005. Radiometric properties of biodegradable films for horticultural protected cultivation. Acta Hort. 691(2): 575-582.

Vox G., Schettini E. 2007. Evaluation of the radiometric properties of starch-based biodegradable films for crop protection. Polym Test 26 (5): 639-651. 